\title{
Electronic Education
}

\author{
D. Vaněček, J. Jirsa
}

\begin{abstract}
The age in which we are living nowadays is characterized by rapid innovation in the development of information and communication technologies (ICT). This innovation has a significant influence on the education process. This paper deals with e-learning.
\end{abstract}

Keywords: e-learning, LMS, computer animation.

\section{Introduction}

The World Wide Web has had a fundamental impact on the paradigm. It also has an impact on education, in particular the way in which information and ideas are transmitted. Computer technology has penetrated into all areas of human activity. It is becoming a part of our everyday life. However, there are still fields in which computers are only slowly beginning to participate and emerge into the foreground. This is particularly true for the social sciences. However, the situation has been changing significantly even there in recent times.

This paper deals with the use of computers in education. We will pay particular attention to elearning and its multimedia capabilities. We will focus on computer animations, which are discussed in greater detail in the second and third parts of this paper.

\section{Electronic education}

The idea of e-learning began with the computer age, and has developed dynamically as the internet has spread and browsers have improved. As recently as 1999, e-learning consisted mainly of static pages. Communication with the teacher either did not work at all, or was limited to e-mails. This phase of computer based learning is also known as Web Based Training (WBT). However, as internet technology developed e-learning courses became more sophisticated and better teacher-student collaboration and feedback became possible. Moreover, thanks to easy up-dating, the content has changed over time and has become more and more multimedia.

Nowadays e-learning is widespread not only in education but also in commercial businesses, which often use it as a major lifelong learning tool for their staff. There are thousands of so-called corporate universities in the world, which push the use and the way of e-learning further.
To-day e-learning is often mentioned by educators, and it is regarded as a means for better teaching, especially in distance teaching. E-learning is a way of enriching and boosting teaching with the use of modern computing technologies (mostly web-based technologies). E-learning changes our view on traditional ways of delivering education, and has also influenced pedagogical and psychological learning theories linked with technologies. If the e-course is well conceived and well created, its use in education is based on modern learning concepts: constructivism and connectivism. The terms remember, recall and learn are enriched by terms like reflect, create and form.

\section{Definition}

The notion of e-learning proves to be difficult to define, in spite of its high frequency of use. Numerous definitions have been proposed, and many of them differ significantly from each other. Usual differences are whether the definition is from a pedagogical viewpoint or from a technological viewpoint, and whether older forms of computer use in education (especially CBT) belong to e-learning (or whether e-learning should only refer to the use of internet technologies). For better understanding we will present some definitions of the notion of e-learning expressed by presentday experts, see [2]:

- For me, e-learning is studying by means of electronic media, be it learning through CDs or through the internet.

- By e-learning I understand educational and training systems (especially on-line systems).

- I understand e-learning as education supported by modern electronic means (computers, media, internet) in distance learning, part-time and fulltime study.

- I imagine e-learning as electronic education, e.g. an educational course created in LMS which is intended for self-study under supervision of 
a teacher who communicates with the student electronically through this environment.

In their definitions of e-learning, experts mostly emphasize its more sophisticated and more exacting forms.

\section{Utilization of e-learning at universities}

E-learning is becoming integrated into the education at many Czech universities, and is created and run by LCMS/LMS systems. This integration of electronic education is of three types at the present time: (see [3])

- Electronic support for full-time study; classical education is mixed with elements of individual work by the student using electronic sources.

- Interactive elements are added to electronic support; classical education is in some cases limited.

- Students have access to electronic courses, and to entire educational cycles. Classical education is limited to a minimum, or is omitted completely. The electronic support is highly interactive, and even tests of knowledge are often administered in this way.

\section{LMS/LCMS systems}

For the ordinary teacher, it is difficult to create a modern interactive electronic course (e-course or elearning course) without expert help. High technical skills are needed. This can affect the teacher's decision-making process, if it is necessary to create an e-course for students on a voluntary basis. The basic skill is in creating web pages. This requires knowledge of HTML documents, and if active elements are used programming skills are also required. There is no reason to assume that each teacher (e.g. a teacher of social sciences) will be willing and technically able to master these computer skills.

Due to these assumptions, computer education systems creators soon began to developed userfriendly systems called Web Content Management Systems - WCMS. Most of these systems run over the internet and they are available via web browsers. Nowadays WCMSs are used for creating and managing web pages, and the user does not need to have programming skills. After logging in to the application, the course creator can insert some content, usually text. After it has been saved, this text is available for other users as a web page (e.g. Wikipedia). WCMSs are very often equipped with advanced features that even an experienced programmer would scarcely be able to implement. These features often include forums, discussions and questionnaires (like in social network pages, e.g. Facebook). All these features are usually well secured and debugged. Here we can mention popular systems such as Drupal and Joomla, or systems based on Wiki.

The idea of utilizing these systems for the purposes of education followed soon after the creation of Learning Content Management Systems - LCMS. There are some differences from regular WCMS, mainly in the specific creation of particular web pages types (online learning courses) and in some additional specific functions. These special functions are characteristic educational tasks, such as setting tests, assigning homework and delivering lectures.

In addition to LCMS there are Learning Management Systems - LMS. These are not suitable for creating e-learning courses, but they are useful for controlling, managing and administering them. The use of LMSs therefore fits well for monitoring students' results, for assigning homework tasks, and for access to separate parts of an e-course (parts created in advance in LCMS). Most systems provide the functions of both LCMS and LMS. The most widespread LMS/LCMS system in the Czech Republic is Moodle.

For technically-oriented subjects, it is necessary to use interactive elements integrated into LMS/LCMS courses. The basic representatives of this branch are animated elements. Skalková made an important contribution. Pedagogical research in the field of education technology has generally emphasized interactivity and hyper-media presentation of knowledge. Sociological research has shown that children and young people are living in an increasingly hyped world. Computers, video and internet have become everyday features of their living environment.

We will now focus on educational computer animation, a significant interactive aspect of electronic learning courses in the framework of LM/LCM systems.

\section{Animation - a multimedia foundation of e-learning}

\section{Animation}

For teaching technical subjects at high schools and universities, for example constructive geometry, it is necessary to develop the students' spatial imagination. Vividness is often crucial for understanding the topic under discussion. The creation of a system of ideas and notions on the basis of directly perceiving real objects is heavily utilized by teachers of technical subjects, but it has its limits. Technical diagrams and photos can be an excellent aid.

Verbally-illustrative vividness, based on a verbal description of phenomena, can prove difficult for students, especially if their personal experience cannot 
be relied on. Thanks to the huge development of the computer technology, new options in support of vividness are now available. This new type of vividness might be called "media vividness". Its main representative is animation.

Animation is essentially an illustrative-demonstrative method [1], combining demonstrations of visual information with dynamic projection.

The reasons for using visual information come from the findings of cognitive psychology. From the point of view of the human psyche, an image is perceived differently than textual information. We can say that an image has a closer relation to the physical world than a verbal description, because its structure preserves the structure of the world. [2] While watching an animation, a student undergoes a process of indirect observation. $\mathrm{He} /$ she observes a mediated model, purposefully perceives the presented facts, and creates notions about the phenomenon or technology. In addition, animation attempts to motivate students for other activities and encourage their interest in the subject.

The option of publishing animations on the internet is closely linked with the didactic principle of continuity and permanency. A student has the option to go back to the animation when working at home. Another advantage of animation is that it can take into account the individual pace of each student. Animation is thus a continuation and extension of usual classwork, basically fulfilling a consolidative function.

\section{Historical development of animation}

The idea of using animation in education is not new. It builds on the basic insight of J. A. Komensky, that people easily remember and acquire new knowledge through visual information, and even better through all their senses. A correctly conceived animation can come very close to fulfilling this requirement.

If we look back into the past for a moment, we can observe that animated presentation of the curriculum has been achieved by various means. When electronic media were not available, animations were made with paper, translucent foil, or specially-lit show cases with an electromechanical drive. Further development was based on electronics and TV broadcasting, which enabled educational programs on TV to be included into traditional classwork. These programmes included some animated elements, but they were made by classical techniques borrowed mainly from the film industry. Subsequent rapid development was connected with the expansion of VCR. It became possible to record broadcast programs on tape, or to play educational programs distributed on VHS video cassettes.

With the development of computer technology, its use in teaching and learning has also changed. The times when a computer served only for teaching programming techniques are long gone. In the process, we have learned the advantages of using computers not only as a tool for presenting a specific course, but also as a tool for testing and evaluating the knowledge of pupils and students. With the rise of the internet, other important changes in methods of education support have emerged. Teachers have created webpages for their students in support of the work done in class, e.g. by publishing study materials. Thus the option of distance study (not to be confused with part-time study!) has appeared, i.e. studying via the still expanding worldwide computer network. Nowadays, we can see the development of entire electronic educational systems with internet support, and the emergence of other conveniences, e.g. animations and simulations.

\section{Features of good didactic animation}

Based on our practical experience of creating technical animations, we will now present some basic features that should be taken into account when designing animations: [3]

- Vividness: this a logical consideration when speaking about animation. Animations should graphically and visually supplement a notion about a topic that is being described theoretically. It is important to know what the intended message is for the student, and what features of the topic should be emphasized.

- Simplicity: when creating the animations, we try to go directly to the point, to portray just a specific point, avoiding esthetic additions. If we add unnecessary extra elements into the animation, the student may get lost and will not know what he/she is supposed to note in the animation, and what the animator is attempting to explain. The principle of the combustion engine can serve as an example. If we want to explain the principle of a four-cylinder engine, we should portray only one cylinder, and on the basis of this one cylinder explain all four strokes that occur during one cycle. We should not add the three other cylinders, which are in a completely different part of the cycle in each stroke. A student would see how the whole system works, but he/she would hardly understand the individual parts of the cycle. By displaying all cylinders at once we could illustrate the function of the engine as a whole. Thus we could consider the animation as illustrative or demonstrative. However, if we want to create a descriptive or telling animation, we should follow the principle that less is often more. If we also want the student to have some fun while watching the animation, and not only stare blankly at the same backgrounds and col- 
ors, the animation should be catchy. Using a number of bright colors will definitely help the catchiness, in contrast with a black and white animation. Colorfulness can be also used for highlighting some parts of the images and for drawing attention to them. When we are explaining the details of a piece of technology, we can always highlight the detail in an appropriate color to make sure that it is obvious what we are talking about and where it is located. Of course, here too the principle of diversity with moderation applies. If we want to retain the student's attention, the animation should be creative. The main issue is, How are we trying to pass on our vision? The more creative the animation is, the more interest it will arouse, and the better it will be remembered by the students. You can certainly remember from your own student years that it matters how a teacher transforms and presents the subject didactically. If a teacher, for example, combines a dry explanation of a physical phenomenon with some witty anecdote about the subject, we are able to recall it even after many years, together with the physical phenomenon. Animation should be used similarly. If we choose a witty design, our graphics can remain in the sub-consciousness of our students for years, together with the phenomenon that they illustrated.

- Adequate length: it is necessary to understand that an excessively long animation can become boring. The attention span of a student has its limits, which should not be crossed. We should try to create a short, clear and diverse animation, so that students will not get bored and start thinking about other things. If students lose their attention in class, there will be a disruption, even if the initial intention was good. If we go to the cinema and the movie is too long and repetitive, we can fall asleep or walk out. Appropriate length always needs to be kept in mind.

- Speed: too much speed is disturbing for the student. It basically ruins the animation if everything we want to say happens in one quick moment. Excessive speed is therefore unsatisfactory. If we slow down the animation, which is in most cases done by adding more images to the animation, the final length and the final number of frames increases. The size of the file of the animation also increases. Making the animation longer can cause a new problem without solving the original problem.

A problem can occur if we want to portray the different speeds of ongoing phenomena within a single animation. For example, a portrayal of the solar system can be very confusing, with each planet rotating round the Sun at a different speed, with different numbers of moons that have different periods of orbit. The student does not know what to concentrate on. For a motivational animation, a high-speed solar system might be suitable, but for an illustrative animation we must find another solution. In this case, it is enough to show each motion separately and spend some time on it, so that the students can comprehend. At the end of the animation we can combine all motions together to represent the real situation, and it will be apparent which planet is faster, when and under what conditions the speed changes.

- Size: the size of the animation depends on the number of frames, or on their length. The smaller the size of the animation, the more accessible it is, because it can be downloaded faster from the internet. The size of an animation can be regulated by the choice of the graphic editor, or by its complexity. The more moving parts the animation has, the more information it will be necessary to save into the final file. Naturally, we do not always have to worry about the size of the graphics. It depends on the way in which our educational course is going to be distributed. If it is to be delivered on CDs, or nowadays rather on DVDs, we can afford to have larger graphic files, because the user will not have to download them from anywhere. The same applies if we create our own animations and keep them on the hard disk drive without any idea of distributing them.

- Use in a class: a scenario is closely linked to the didactic function of the animation - whether it is to serve for motivating, for simulating and understanding patterns, for practicing or for testing.

\section{Technological aspects of animation}

The first didactic animation types were created as animated GIFs. This format was suitable for web presentation purposes. It is based on a common cartoon concept, where the animation consists of a sequence of single pictures. We create the series of pictures, which we then merge into one final animation with a GIF file extension. It is easy to create and edit animations of this kind, because shareware or freeware software tools are available all over the internet (e.g. GIF Construction Set for Windows). There is no need to obtain expensive licenses for commercial tools such as Adobe Photoshop. The main disadvantage of these animations is their size. We have to remember that we use a sequence of single pictures. The final size of the animation is therefore 
the sum of all included pictures, and can be large. This can be an important consideration when there is a slow internet connection and the student may have to wait some minutes for the whole animation to be downloaded into his computer. Another issue is the degree of animation. Classical film is based on 24 frames per second. If we want to achieve cinematic animation quality, we have to create animation with 24 frames per second, but this leads to a large file size. An alternative is to use less than 24 frames, e.g. just one per second. This solution will lead to inferior visual effects and the animation will be ripped. The usage of such sequences is therefore only suitable for illustrating some simple idea, or for adding some interesting decoration. It is necessary to use animated GIFs appropriately, otherwise we can achieve the opposite of what was intended. Another disadvantage of GIFs is the absence of any audio track.

Dynamic HTML. The earliest concept of web sites was based on the idea of static information sites, without any changing content, though a new page might be added at any time. This property is characteristic of the basic HTML web site language (Hyper Text Markup Language). The basic elements of this language are tags, which tell the web browser how to display a certain part (font, hypertext link, etc.) As the internet progressed, static web content became less and less adequate. Web developers wanted to add dynamically changing parts of web sites for users to view. This feature was allowed with Dynamic HTML (or DHTML) technology. Complex scripting languages are used, like JavaScript. These languages provide access to the Document Object Model (DOM) within the user's browser. However, DHTML is not suitable for creating animation. It can move static pictures in the browser window due to the properties of DOM. If we move several graphical elements in different directions, we can get some degree of graphic animation.

The two technologies, GIF and DHTML, are automatically recognized by the web browser, without any additional programs or plug-ins. However, it is hard to make any DHTML animation that will be correctly displayed in all web browsers. This is its disadvantage against GIF animation. It is also rather more difficult to program animations, but fortunately there are software tools that can easily create the initial code for our web page. DHTML itself is not very efficient for web animation purposes, because it only involves moving static pictures inside the window area. We cannot make any other types of animation, such as shape or color transformations. However, these animations are smoother than animated GIFs. More variable web animations can be created with the use of more sophisticated web browser plugins.
Java applets. Another way to create web animation is by using multiplatform network programming Java language. In Java, we can create small applications downloadable and running in the web browser, provided we have installed the necessary plug-in. These applets are small reduced software applications which cooperate with the web browser. The main advantage of Java is its cross-platform orientation and its ability to run on several operating systems. We can create several interactive animations, including raster or vector based graphics, or we can mix it with other web page elements.

Adobe Flash (or Shockwave Flash). Adobe Flash or Adobe Director are applications that enable any graphic idea of the author to be animated. Both are widely-used software applications. In 2003, more than 97 percent of all internet users visited web sites with Macromedia Flash content (accordingly to information provided by Macromedia corporation). For this reason there are Adobe extension modules (plugins) for the widely-used web browsers that enable animation to be shown inside the web browser window. Of course, this is a very user-friendly feature, because we can get the requested content by one click of the mouse. Even if we do not have plug-ins installed, most web browsers offer automatic download of plug-ins from relevant web sites. Thus there is no need to search for them all over the internet. However, we can also download them manually from the Adobe web site if we want. The advantage of Adobe Flash or Adobe Director is that they create small files which are easily and quickly downloadable. This is due to the utilization of vector graphics inside their file format. We therefore do not need to transfer whole pictures over the net, but only vectors of their changes. The second benefit is the popularity of this graphical format. It is a well-known format in the community of animation creators.

The third advantage concerns downloading. Even if the animation file is large, the user does not have to wait for long. The concept of Flash animations allows the animation to start playing before the whole file has been fully downloaded. These concurrent playing and downloading activities are very useful, because the user can immediately focus on the information that is being presented, and does not need to think about the rest of file. The question is which of them to choose - Flash or Director? In most cases the significant parameter is price. Thus we will probably choose the Adobe Flash, which is cheaper than Adobe Director.

The file extension of Flash animation is fla. This is the source file type of animation which is only editable, and cannot be played directly out of the editor. We must therefore publish the animation into a playable format SWF (ShockWave Flash) or optionally into other formats like EXE or HTML. 
Flash animation can nowadays be found in many web sites, see the number of interactive advertisement banners. Flash format also includes the programming language. This feature allows the creation of several interactive environments to fulfil the author's graphic ideas.

Wink. Wink is free software tool. It can create animations directly by recording screenshots. We can utilize it especially for topics where the students work with computer workstations. In this case we need to show students some new actions, immediately after which they should try them themselves. Examples of these activities are: algorithm programming, courses in computer graphics or presentation of application features. The principle of Wink is based on making screenshots. First, we choose the required recording area on our screen. It is then minimized and waits for a signal from the user. After the right combination of keys has been pressed, the recording starts, while the tutor normally works, e.g. shows work with a new application. The tutor works continuously, and the Wink concurrently takes snapshots of the selected screen area. When the recording is finished (by pressing the same combination again), smooth animation can be created from the sequence of recorded screenshots.

If we find a group of identical screenshots due to our longer explanation, we can rip these screenshots out and leave only one of them. Then we set a longer presentation time for this single screenshot. This leads to considerable saving of file. We can also add some additional comments, graphic symbols or pictures. The final animation looks like a video that is exportable into several file formats, including Flash or PDF. Then it has the same advantages as we mentioned above. The tutor can also add some audio comments that explain the actual situation on the screen. There is no reason to make this animation only from screenshots. We can also compose it from other picture formats e.g. JPG, GIF, BMP. The major advantages of Wink can be observed when students have to emulate the computer activity of a tutor. The main utilization of Wink is for informatics. Wink is used in a practical way at the technical electrical industry secondary school in Jecna Street, in Prague. This kind of education is used at the school for teaching computer languages. Wink is very popular with teachers and with students.
We should point out that the list of software applications mentioned here is incomplete. There are many other tools that are more or less suitable for creating animation, and as technology progresses we can anticipate further extension and innovation of programs of this sort.

\section{Conclusion}

The goal of this paper was to present to the reader some key issues in electronic education and some opportunities in multimedia. We have provided an introduction to technical animation as a fundamental multimedia aspect of electronic learning. We present a taxonomy of technical animation in the paper that follows.

\section{References}

[1] Vaněček, D.: Informační a komunikační technologie ve vzdělávání. Praha : ČVUT, 2008. ISBN 978-80-01-04087-4.

[2] Kassin, S.: Psychologie. Computer Press, 2007. ISBN 978-80-251-1716-3.

[3] Kropelnický, R.: Využití animace při tvorbě elearningového kurzu, BP MÚVS ČVUT, Praha 2007, ved. práce D. Vaněček.

[4] Vargová, M.: Metodika pracovnej výchovy a pracovného vyučovania. Nitra : PF UKF, 2007. ISBN 978-80-8094-171-0.

Ing. Paed. IGIP. David Vaněček, Ph.D.

E-mail: david.vanecek@muvs.cvut.cz

Czech Technical University in Prague

Masaryk Institute of Advanced Studies

Department of Engineering Pedagogy

Horská 3, 12800 Praha 2, Czech Republic

Ing. Bc. Jan Jirsa

E-mail: jirsaj@fel.cvut.cz

Czech Technical University in Prague

Faculty of Electrical Engineering

Technická 2, 16627 Praha 6, Czech Republic 